\title{
Impact of Initial Computed Tomography Findings on Management of Atypical Urinary Cytology of the Upper Urinary Tract
}

\author{
Kotaro Takemura ${ }^{a}$ Taketo Kawai ${ }^{a} \quad$ Yusuke Sato $^{a} \quad$ Jimpei Miyakawa ${ }^{a}$ \\ Satoru Taguchi ${ }^{b}$ Yoshiyuki Akiyama ${ }^{a}$ Yuta Yamada ${ }^{a}$ Masaki Nakamura ${ }^{a}$

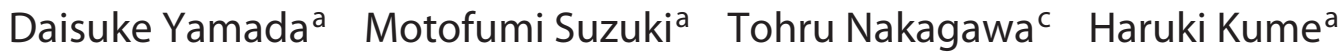 \\ aDepartment of Urology, Graduate School of Medicine, The University of Tokyo, Tokyo, Japan; bepartment of \\ Urology, Kyorin University School of Medicine, Tokyo, Japan; 'Department of Urology, Teikyo University School of \\ Medicine, Tokyo, Japan
}

\section{Keywords \\ Upper urinary tract urothelial carcinoma $\cdot$ Upper urinary tract cytology · Atypical · Class III · Repeated RP . Ureteroscopy · Ureterorenoscopy}

\begin{abstract}
Introduction: Management of patients with atypical urinary cytology (class III) of the upper urinary tract is often complicated because some patients develop upper urinary tract urothelial carcinoma (UTUC). Here, we aimed to help define the optimal management of these patients. Methods: We investigated 31 patients who underwent retrograde ureteropyelography (RP) and were diagnosed with atypical findings of upper urinary tract cytology. Results: UTUC was revealed in 17 of 31 patients during the follow-up period of 1 year or longer. Tumor-like lesions and wall thickening in the upper urinary tract on initial computed tomography (CT) were significant predictors of UTUC ( $p=0.0002$ and $p=$ 0.012 , respectively). All 11 patients with tumor-like lesions and 3 of 8 patients with wall thickening on initial CT underwent nephroureterectomy, and UTUC was confirmed histologically. Moreover, 3 of 12 patients with hydronephrosis only or with normal findings later went on to develop UTUC.
\end{abstract}

karger@karger.com www.karger.com/uin

Karger $\stackrel{\text { ' }}{=}$

GOPEN ACCESS
(C) 2021 The Author(s)

Published by S. Karger AG, Basel

This is an Open Access article licensed under the Creative Commons Attribution-NonCommercial-4.0 International License (CC BY-NC) (http://www.karger.com/Services/OpenAccessLicense), applicable to the online version of the article only. Usage and distribution for commercial purposes requires written permission.
Repeated RP performed within 6 months from the initial RP was able to distinguish patients with UTUC from those without, even in individuals with normal CT findings. Discussion/ Conclusion: Repeated RP based on initial CT findings is recommended in patients with atypical urinary cytology of the upper urinary tract. Nephroureterectomy without repeated $\mathrm{RP}$ may be warranted in patients with tumor-like lesions on initial CT findings.

(c) 2021 The Author(s)

Published by S. Karger AG, Basel

\section{Introduction}

Upper urinary tract urothelial carcinoma (UTUC) accounts for $5-10 \%$ of urothelial carcinomas [1-3]. Because $60 \%$ of UTUC patients have invasive cancer at diagnosis, identification of tumors in earlier stages is crucial for disease management. However, microscopic hematuria, the most common symptom of UTUC, can be often overlooked, which might result in delayed diagnosis [4].

Upper urinary tract cytology, retrograde ureteropyelography (RP), and ureterorenoscopy (or ureteroscopy) are widely used in the diagnosis of UTUC. Urinary cytology of the upper urinary tract is generally accompanied 

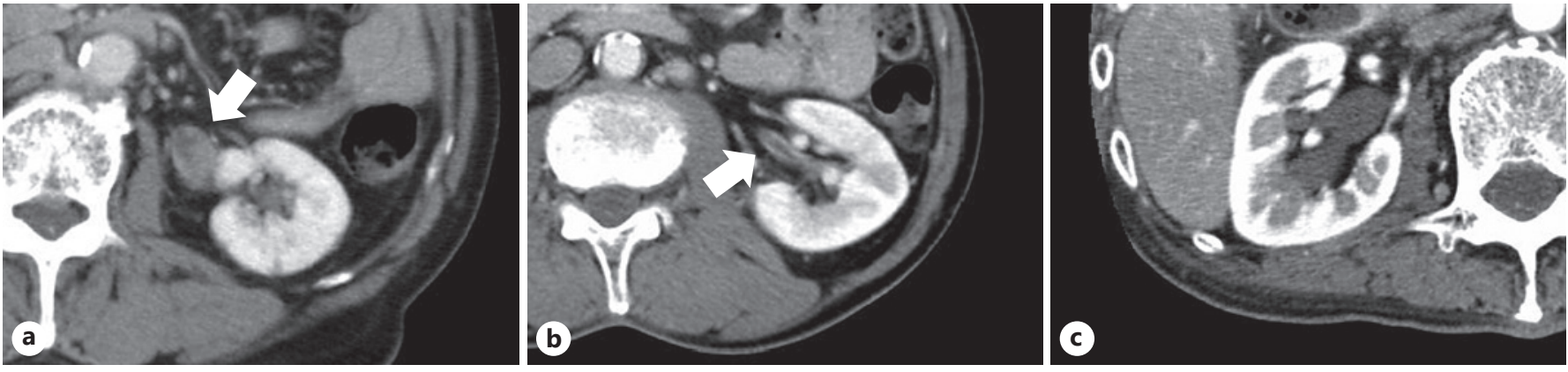

Fig. 1. Classification based on the initial CT findings. Tumor-like lesions (arrow); Group A (a), wall thickening (arrow); Group B (b), hydronephrosis; Group C (c). CT, computed tomography.

by RP, and specimens are collected by ureteral catheterization before application of a contrast agent for RP. The sensitivity of upper urinary tract cytology is relatively low (43-78\%) in UTUC, compared with those of voided urinary cytology in bladder cancer (55-90\%) [5]. This presents a significant risk in terms of false-negative results in patients with actual UTUC. Thus, the management of patients with atypical findings (class III) of upper urinary tract cytology is often complicated. In this study, we investigated the development of UTUC in patients with atypical urinary cytology of the upper urinary tract in order to help define the optimal management of this disease.

\section{Methods}

Between 2008 and 2018 at the University of Tokyo Hospital, 34 patients with suspected UTUC following computed tomography (CT) or voided urinary cytology underwent RP and were diagnosed with atypical findings (class III) of upper urinary tract cytology. Urinary cytology was defined as follows: class V, conclusive for malignancy; class IV, strongly suggestive for malignancy; class III, atypical but not conclusive for malignancy; and classes I and II, negative for malignancy. We analyzed the clinical data of 31 patients for whom UTUC was revealed during the follow-up period of 1 year or longer; the other 3 patients were excluded from the analysis because of the short observation period or lack of information. After the initial RP, repeated RP including upper urinary tract cytology with/without ureterorenoscopy was performed at the discretion of the attending physician within 6 months, regardless of changes in findings of CT or voided urinary cytology. On the other hand, those patients for whom observation was continued without repeated RP were followed by CT scans and voided urinary cytology every 3-6 months, and reexamination of RP (called nonscheduled RP) with/without ureterorenoscopy was considered when changes appear in CT and/or cytology findings. A positive UTUC diagnosis was defined as patients who were diagnosed with UTUC histologically by biopsy (including at the ini- tial RP) or nephroureterectomy during the follow-up period. A negative UTUC diagnosis was defined as patients who did not develop UTUC during the follow-up period of 1 year or longer. Fisher's exact test was used for statistical analysis, and a $p$ value $<0.05$ was considered significant.

\section{Results}

Table 1 shows the findings of the examination and management of 31 patients with atypical urinary cytology of the upper urinary tract. According to the initial CT findings in the upper urinary tract, we divided the patients into 4 groups: tumor-like lesions in 11 (Group A; Fig. 1a), wall thickening without tumor-like lesions in 8 (Group B; Fig. 1b), hydronephrosis without tumor-like lesions or wall thickening in 4 (Group C; Fig. 1c), and normal findings in 8 (Group D).

In Group A, all 11 patients underwent nephroureterectomy and UTUC was confirmed histologically. Five patients had undergone nephroureterectomy immediately, without repeated RP, ureterorenoscopy, or biopsy. In Group B, UTUC was revealed in 3 of 8 patients and the remaining 5 patients were under surveillance without evidence of UTUC at the median follow-up period of 47 months (23-132 months). In Group C, UTUC developed in one of 4 patients; this patient was diagnosed with UTUC by nonscheduled RP following positive voided urinary cytology and appearance of tumor-like lesions in the ureter upon CT analysis. In Group D, UTUC was revealed in 2 of 8 patients. One positive patient had an extremely small tumor at the vesicoureteral junction that was revealed by ureterorenoscopy; this tumor was resected endoscopically. The other was diagnosed with carcinoma in situ of the upper urinary tract by repeated RP. 
Table 1. Examination and management of 31 patients with atypical urinary cytology of the upper urinary tract

\begin{tabular}{|c|c|c|c|c|c|c|c|c|c|}
\hline \multirow[t]{2}{*}{ Group } & \multirow{2}{*}{$\begin{array}{l}\text { Initial CT } \\
\text { findings }\end{array}$} & \multirow[t]{2}{*}{$N$} & \multicolumn{4}{|c|}{ Initial RP, cytology with/without ureterorenoscopy, biopsy } & \multicolumn{3}{|l|}{ Management and outcome } \\
\hline & & & $\mathrm{RP}$ & $\begin{array}{l}\text { upper tract } \\
\text { urinary cytology }\end{array}$ & ureterorenoscopy & biopsy & management $^{*}$ & $\begin{array}{l}\text { histological grading } \\
\text { of UTUC }\end{array}$ & $\begin{array}{l}\text { TNM staging of } \\
\text { UTUC at diagnosis } \\
\text { or follow-up }\end{array}$ \\
\hline \multirow[t]{4}{*}{ Group A } & \multirow[t]{4}{*}{$\begin{array}{l}\text { Tumor-like lesions } \\
(n=11)\end{array}$} & 5 & Defect & Class III & Tumor observed & Positive for UTUC & Nephroureterectomy & $\begin{array}{l}\text { (1) G3/high, (2)G3/ } \\
\text { high, (3) G3/high, } \\
\text { (4) G3/high, (5) G3/ } \\
\text { high }\end{array}$ & $\begin{array}{l}\text { (1) TisNom0, } \\
\text { (2) TaNOM0, } \\
\text { (3) T1N0M0, } \\
\text { (4) T3N0M0, } \\
\text { (5) T4N0M0 }\end{array}$ \\
\hline & & 1 & Defect & Class III & $\begin{array}{l}\text { Poor observation due to } \\
\text { bleeding }\end{array}$ & $\begin{array}{l}\text { Negative for } \\
\text { UTUC }\end{array}$ & $\begin{array}{l}\text { Repeated RP; positive o nephrou- } \\
\text { reterectomy }\end{array}$ & G3/high & T3N2M0 \\
\hline & & 4 & Defect & Class III & Not performed & Not performed & $\begin{array}{l}\text { Nephroureterectomy without re- } \\
\text { peated RP }\end{array}$ & $\begin{array}{l}\text { (1)G3/high, (2)G2/ } \\
\text { high, (3) G3/high, } \\
\text { (4) G3/high }\end{array}$ & $\begin{array}{l}\text { (1) TaNoM0, } \\
\text { (2) T1N0M0, } \\
\text { (3) T3N0M0, } \\
\text { (4) T3N1M0 }\end{array}$ \\
\hline & & 1 & Unknown & Class III & Not performed & Not performed & $\begin{array}{l}\text { Nephroureterectomy without re- } \\
\text { peated RP }\end{array}$ & G2/low & TaN0M0 \\
\hline \multirow[t]{7}{*}{ Group B } & \multirow{7}{*}{$\begin{array}{l}\text { Wall thickening with- } \\
\text { out tumor-like lesions } \\
(n=8)\end{array}$} & 1 & Defect & Class III & Tumor observed & Positive for UTUC & Nephroureterectomy & G3/high & T3N0M0 \\
\hline & & 1 & Negative & Class III & Tumor observed & Positive for UTUC & Nephroureterectomy & G3/high & T3N1M0 \\
\hline & & 1 & Negative & Class III & No tumor observed & $\begin{array}{l}\text { Negative for } \\
\text { UTUC }\end{array}$ & Repeated RP; negative & na & NED at 132 months \\
\hline & & 1 & Negative & Class III & No tumor observed & Not performed & Repeated RP; negative & na & NED at 51 months \\
\hline & & 1 & Stenosis & Class III & Not performed & Not performed & $\begin{array}{l}\text { Observation dthsascheduled RP; } \\
\text { positive onnephroureterectomy }\end{array}$ & G3/high & TisN2M0 \\
\hline & & 1 & Negative & Class III & No tumor observed & $\begin{array}{l}\text { Negative for } \\
\text { UTUC }\end{array}$ & $\begin{array}{l}\text { Observation } \rightarrow \text { nonscheduled RP; } \\
\text { negative }\end{array}$ & na & NED at 23 months \\
\hline & & 2 & Negative & Class III & Not performed & Not performed & Observation & na & $\begin{array}{l}\text { NED at } 42 \text { and } 131 \\
\text { months }\end{array}$ \\
\hline \multirow[t]{3}{*}{ Group C } & \multirow{3}{*}{$\begin{array}{l}\text { Hydronephrosis with- } \\
\text { out tumor-like lesions } \\
\text { or wall thickening }(n= \\
4)\end{array}$} & 1 & Negative & Class III & No tumor observed & $\begin{array}{l}\text { Negative for } \\
\text { UTUC }\end{array}$ & Repeated RP; negative & na & NED at 77 months \\
\hline & & 1 & Stenosis & Class III & Not performed & Not performed & $\begin{array}{l}\text { Observation dthsascheduled RP } \\
\text { with biopsy; positive }\end{array}$ & G3/high & T1N0M1 \\
\hline & & 2 & Stenosis & Class III & Not performed & Not performed & Observation & na & $\begin{array}{l}\text { NED at } 16 \text { and } 80 \\
\text { months }\end{array}$ \\
\hline \multirow[t]{6}{*}{ Group D } & \multirow[t]{6}{*}{ Normal findings $(n=8)$} & & Negative & Class III & Tumor observed & Positive for UTUC & Endoscopic resection & G2/low & TaNoM0 \\
\hline & & 1 & Negative & Class III & Not performed & Not performed & $\begin{array}{l}\text { Repeated RP; positive } \rightarrow \text { enephrou- } \\
\text { reterectomy }\end{array}$ & G3/high & TisN0M0 \\
\hline & & 1 & Stenosis & Class III & Not performed & Not performed & Repeated RP; negative & na & NED at 15 months \\
\hline & & 1 & Negative & Class III & Not performed & Not performed & Repeated RP; negative & na & NED at 26 months \\
\hline & & 1 & Stenosis & Class III & Not performed & Not performed & Observation & na & NED at 53 months \\
\hline & & 3 & Negative & Class III & Not performed & Not performed & Observation & na & $\begin{array}{l}\text { NED at } 17,34 \text {, and } \\
78 \text { months }\end{array}$ \\
\hline
\end{tabular}

na, not applicable; NED, no evidence of disease; UTUC, urinary tract urothelial carcinoma; CT, computed tomography. * Repeated RP and nonscheduled RP include reexamination of upper tract urinary cytology with/without ureterorenoscopy and biopsy. Repeated RP was performed within 6 months after initial RP. Nonscheduled RP was performed following changes in CT and/or cytology findings after observation.

In total, UTUC was revealed in 17 of 31 patients over a median follow-up period of 30 months (0.2-126 months). UTUC in 15 of 17 patients was high-grade. Patients without UTUC were followed for a median of 47 months (15-132 months).

Tumor-like lesions and wall thickening in the upper urinary tract on initial CT findings were significantly cor- related with UTUC positivity $(p=0.0002$ and $p=0.012$, respectively; Table 2). Although hydronephrosis was not significant ( $p=0.65)$, as many as 3 of 12 patients with hydronephrosis only or normal findings later went on to develop UTUC.

Repeated RP with/without ureterorenoscopy was performed in 7 patients; 2 patients were diagnosed with 
Table 2. Correlation between initial CT findings and UTUC positivity

\begin{tabular}{llll}
\hline Initial CT findings & $\begin{array}{l}\text { Total, } \\
n\end{array}$ & $\begin{array}{l}\text { UTUC } \\
\text { positive, } \\
n(\%)\end{array}$ & $\begin{array}{l}\text { UTUC negative, } \\
n(\%)\end{array}$ \\
\end{tabular}

\begin{tabular}{lcccc} 
Tumor-like lesions & & & & \\
Yes & 11 & $11(100)$ & $0(0)$ & 0.0002 \\
No & 20 & $6(30)$ & $14(70)$ & \\
\hline
\end{tabular}

\begin{tabular}{lrrrr}
\hline Wall thickening* & & & & \\
Yes & 19 & $14(74)$ & $5(26)$ & 0.012 \\
No & 12 & $3(25)$ & $9(75)$ & \\
\hline
\end{tabular}

Hydronephrosis ${ }^{\dagger}$

\begin{tabular}{lrrrr} 
Yes & 18 & $11(61)$ & $7(39)$ & 0.65 \\
No & 13 & $6(46)$ & $7(54)$ & \\
\hline
\end{tabular}

Any findings

\begin{tabular}{lrrrr} 
Yes & 23 & $15(65)$ & $8(35)$ & 0.097 \\
No & 8 & $2(25)$ & $6(75)$ & \\
\hline
\end{tabular}

UTUC, urinary tract urothelial carcinoma; CT, computed tomography. * Including the cases with tumor-like lesions. ${ }^{\dagger}$ Including the cases with tumor-like lesions or wall thickening.

UTUC, whereas 5 with negative RP were followed with no evidence of UTUC over a median period of 51 months (15-132 months). This suggests that repeated RP was a robust method for distinguishing patients with UTUC from those without. On the other hand, nonscheduled RP was performed in 3 patients, and UTUC was found in 2, all of whom had metastatic disease, suggesting a delay in correct diagnosis.

\section{Discussion/Conclusion}

In patients suspected of having UTUC following CT and/or voided urinary cytology, the combination of RP, upper urinary tract cytology, and ureterorenoscopy increases the sensitivity of UTUC diagnosis. The sensitivity of the combined examinations is 87.5 and $100 \%$ for lowand high-grade UTUC, respectively [5]. The predictive value of positive upper urinary tract cytology is high in invasive or high-grade UTUC [6]. The addition of a FISH test may increase both sensitivity and specificity $[7,8]$. Meanwhile, positive voided urinary cytology before nephroureterectomy is associated with intravesical recurrence [6].

According to a previous study, 1,320 of 16,299 urinary cytology specimens $(8.1 \%)$ including voided cytology or upper urinary tract cytology were diagnosed as atypical, and 271 of 1,320 initial atypical urinary specimens (21\%) progressed to positive cytology or confirmed surgical pathology [8]. Although the frequency of atypical upper urinary tract specimens was relatively low in the aforementioned study ( 82 of 2,$482 ; 3.3 \%$ ), patients presenting with an atypical upper urinary tract specimen frequently progressed to a malignant diagnosis (31 of $82 ; 38 \%$ ) which was often high-grade (17 of 82; 21\%) [8]. Thus, patients with atypical cells identified during upper urinary tract cytology should be carefully managed. Indeed, in our study, high-grade UTUC developed in 4 of 18 patients during follow-up despite not being diagnosed at the initial evaluation. Furthermore, UTUC in 15 of 17 patients was high-grade. This result suggests that high-grade cancer cells do not necessarily flow out into the urine even with high-grade UTUC, emphasizing the need for careful follow-up.

We have demonstrated that tumor-like lesions and wall thickening in the upper urinary tract on initial CT findings are significant predictors of UTUC. Especially, all patients with tumor-like lesions were UTUC positive. These results suggest that immediate nephroureterectomy without repeated RP may be warranted in patients with tumor-like lesions on initial CT under sufficient informed consent. Although wall thickening was also found to be a significant predictor in UTUC diagnosis, the actual incidence of UTUC was only 3 in 8 patients. Further studies are required in order to evaluate the predictive potential of wall thickening, and we currently advise against performing immediate surgery.

In this study, repeated RP refers to scheduled examination performed within 6 months after the initial RP regardless of changes in findings of $\mathrm{CT}$ or voided urinary cytology. This was discriminated from nonscheduled RP, which was performed following changes in CT and/or cytology findings after observation. Repeated RP appears to be a robust strategy for distinguishing patients with UTUC from those without 2 patients were diagnosed with UTUC and 5 patients with negative results had no evidence of disease at the median follow-up period of 51 months. On the other hand, the diagnosis of UTUC might have been delayed in 2 nonscheduled $\mathrm{RP}$ patients in whom metastatic disease was found concomitant with eventual UTUC diagnosis. These results suggest that repeated RP should be considered, especially in patients suspected of having disease at the initial examination.

The present study is associated with some limitations. The primary limitation is the small sample size. The ob- 
servation period after the initial RP may not have been long enough to confirm UTUC positivity in some patients. Moreover, the diagnosis of urinary cytology varies depending on the facility or pathologists. Further studies will be required to support the initial findings of our study.

Our results suggest that repeated RP with/without ureterorenoscopy based on initial CT findings in the upper urinary tract or other factors should be adopted in clinical practice. This may improve the management of patients with atypical urinary cytology of the upper urinary tract and simplify what has historically been a complex disease to manage.

\section{Statement of Ethics}

This study was approved by the Ethics Committee at the University of Tokyo Hospital (Approval number: 3124). Written informed consent to participate and for publication was obtained from the patients.

\section{Conflict of Interest Statement}

The authors declare no conflicts of interest.

\section{Funding Sources}

The authors did not receive any funding.

\section{Author Contributions}

K.T. collected data and wrote the manuscripts. T.K. contributed to concept of this paper, interpreted the data, and prepared the manuscripts. Y.S. and J.M. collected data. S.T., Y.A., Y.Y., M.N., D.Y., M.S., and T.N. reviewed the manuscripts. H.K. contributed to concept of this paper and reviewed the manuscripts. All authors read and approved the final manuscripts.

\section{References}

1 Siegel RL, Miller KD, Jemal A. Cancer statistics, 2016. CA Cancer J Clin. 2016;66(1):7-30.

2 Munoz JJ, Ellison LM. Upper tract urothelial neoplasms: incidence and survival during the last 2 decades. J Urol. 2000;164(5):1523-5.

3 Soria F, Shariat SF, Lerner SP, Fritsche HM, Rink M, Kassouf W, et al. Epidemiology, diagnosis, preoperative evaluation and prognostic assessment of upper-tract urothelial carcinoma (UTUC). World J Urol. 2017; 35(3):379-87.

4 Margulis V, Shariat SF, Matin SF, Kamat AM, Zigeuner R, Kikuchi E, et al. Outcomes of rad- ical nephroureterectomy: a series from the upper tract urothelial carcinoma collaboration. Cancer. 2009;115(6):1224-33.

5 Wang L, Pambuccian SE, Wojcik EM, Barkan GA. Diagnosis of upper tract urothelial carcinoma: a comparative study of urinary cytology and surgical biopsy. J Am Soc Cytopathol. 2015;4(1):3-9.

6 Tanaka N, Kikuchi E, Kanao K, Matsumoto K, Shirotake S, Kobayashi H, et al. The predictive value of positive urine cytology for outcomes following radical nephroureterectomy in patients with primary upper tract urothelial carcinoma: a multi-institutional study. Urol Oncol. 2014;32(1):4826.

7 Xu C, Zeng Q, Hou J, Gao L, Zhang Z, Xu W, et al. Utility of a modality combining FISH and cytology in upper tract urothelial carcinoma detection in voided urine samples of Chinese patients. Urology. 2011;77(3):63641.

8 Muus Ubago J, Mehta V, Wojcik EM, Barkan GA. Evaluation of atypical urine cytology progression to malignancy. Cancer Cytopathol. 2013;121(7):387-91. 